\title{
Using glycated haemoglobin testing to simplify diabetes screening in remote Aboriginal Australian health care settings
}

\section{The strength \\ of our study \\ is that it \\ reflects the \\ practicalities \\ of diabetes \\ detection \\ in remote \\ locations}

\section{Julia V Marley}

PGDipSc, PGDipPolSt, PhD ${ }^{1.2}$

May Sian Oh

MBBS, FRACGP, MIH

Nyssa T Hadgraft

MPH, BSc(Hons)

Sally L Singleton MPH\&TM, FRACGP, FACRRM ${ }^{2}$

Kim Isaacs MBBS, FRACGP, BCom²

David N Atkinson MBBS, MPH

1 Rural Clinical School of Australia, University of Western Australia Broome, WA.

2 Kimberley Aboriginal Medical Services, Broome, WA

Julia.Marley@ rcswa.edu.au

doi: 10.5694/mjal4.01575

Editorial p 7
E arly identification of diabetes and associated complications provides an opportunity to start effective preventive treatment that reduces the subsequent development or progression of macrovascular and microvascular disease. ${ }^{1-3}$ However, diabetes remains undiagnosed in up to $50 \%$ of people with the disorder. ${ }^{2-4}$

Delayed diagnosis is due in part to the use of an algorithm that relies on the assessment of glucose levels and, if the results are equivocal, a follow-up oral glucose tolerance test (OGTT). ${ }^{5}$ This complicated algorithm can significantly delay informing and educating the patient. ${ }^{6}$ In contrast to glucose testing, assessment of glycated haemoglobin $\mathrm{A}\left(\mathrm{HbA}_{1 \mathrm{c}}\right)$ requires no fasting. ${ }^{7}$ This makes it more suitable for opportunistic testing, and results in fewer missed diagnoses. ${ }^{8}$

The American Diabetes Association (ADA) guidelines have included laboratory $\mathrm{HbA}_{1 \mathrm{c}}$ testing for diagnosing diabetes since $2010 .{ }^{7} \mathrm{HbA}_{1 \mathrm{c}}$ testing is endorsed by the World Health Organization, ${ }^{9}$ and is recommended for diagnosing diabetes in the United Kingdom and New Zealand. ${ }^{10,11}$ In 2012, the Australian Diabetes Society (ADS) expert committee advised that $\mathrm{HbA}_{1 \mathrm{c}}$ assessment can be used to diagnose diabetes, and applied for a corresponding Medicare Benefits Schedule (MBS) rebate. ${ }^{12,13}$ This was added on 1 November 2014 after the Medical Services Advisory Committee (MSAC) provided advice to the Minister for Health in mid 2014. . $^{13,14}$

MSAC and the ADS agreed that pointof-care (POC) $\mathrm{HbA}_{1 \mathrm{c}}$ testing was not within the scope of this application. Laboratory $\mathrm{HbA}_{1 \mathrm{c}}$ tests from the Kimberley region of northern Western Australia are analysed in Perth, over $1600 \mathrm{~km}$ away, which can lead to significant delays in receiving test results. In a number of studies, $\mathrm{POC} \mathrm{HbA}_{1 \mathrm{c}}$ results have been shown to be closely correlated with laboratory-based

\section{Abstract}

Objectives: To determine whether a combination of point-of-care (POC) and laboratory glycated haemoglobin $\mathrm{A}\left(\mathrm{HbA}_{\mathrm{lc}}\right)$ testing $\left(\mathrm{HbA}_{\mathrm{lc}}\right.$ algorithm) is more effective in testing for diabetes in everyday practice in remote Australian Aboriginal primary health care, by providing a more rapid definitive result and diagnosing more cases than the standard glucose algorithm.

Design: Cross-sectional study that independently classified participants using both diagnostic algorithms and compared their outcomes.

Participants: Two hundred and fifty-five Aboriginal Australians aged 15 years or more without confirmed diabetes and due for diabetes testing at participating clinics.

Setting: Six primary health care sites in the Kimberley region of Western Australia from 1 September 2011 to 30 November 2013.

Main outcome measures: Number of participants with a definitive test result, a completed algorithm and a diagnosis of diabetes; time taken to deliver a test result.

Results: Participants were significantly more likely to have a definitive result within 7 days ( 249 v 199 of 255 participants; $P<0.001$ ), be followed up if an initial laboratory measurement was abnormal (92 v 74 of 167 participants; $P=0.005$ ), and be diagnosed with diabetes ( $15 \vee 4$ of 255 participants; $P=0.003$ ) using the $\mathrm{HbA}_{1 c}$ than with the glucose algorithm. Eight participants subsequently diagnosed with diabetes (four using the $\mathrm{HbA}_{1 c}$ test, four with additional oral glucose tolerance tests that would not normally have been requested) were incorrectly classified as normal by the glucose algorithm. No participants with normal $\mathrm{HbA}_{1 c}$ measurements were subsequently diagnosed with diabetes.

Conclusions: Use of POC $\mathrm{HbA}_{1 \mathrm{c}}$ testing and collection of venous blood on the same day for a confirmatory laboratory $\mathrm{Hb} A_{1 c}$ testing if the $\mathrm{POC} \mathrm{Hb} A_{l c}$ value is abnormal may simplify diabetes testing in remote areas, provide more timely diagnoses, and increase case detection.

results ${ }^{15-17}$ and the POC $\mathrm{HbA}_{1 \mathrm{c}}$ process has been accepted by Australian Aboriginal Medical Services for the management of diabetes. ${ }^{18}$

The availability of immediate results is likely to further improve diagnosis of diabetes in remote areas and the timeliness of starting treatment. We aimed to determine whether a combination of POC and laboratory $\mathrm{HbA}_{1 \mathrm{c}}$ testing, in real-world settings using existing processes for $\mathrm{HbA}_{1 \mathrm{c}}$ assessment, is an effective method of testing for diabetes in remote Kimberley Aboriginal people when compared with the standard glucose algorithm. ${ }^{19}$

\section{Methods}

Data were collected by local health care providers from 1 September
2011 to 30 November 2013 at six Kimberley sites. All Aboriginal and Torres Strait Islander people in the Kimberley region aged 15 years and older are regarded as being at high risk of developing diabetes, and local protocols recommend that they be tested annually. ${ }^{19}$ Aboriginal and/ or Torres Strait Islander people who did not have confirmed diabetes and who were due for diabetes testing and attending participating clinics were invited to take part. A cross-sectional design was used to compare the effectiveness of a new model of detecting diabetes (the $\mathrm{HbA}_{1 \mathrm{c}}$ algorithm) with the standard model (the glucose algorithm) in diagnosing prediabetes and diabetes. The study was conducted on an opportunistic basis according to available clinic resources. 


\section{$\mathrm{HbA}_{1 \mathrm{c}}$ and glucose tests}

Clinic staff recorded patient consent, determined fasting status, conducted initial POC $\mathrm{HbA}_{1 \mathrm{c}}$ tests and collected blood for laboratory $\mathrm{HbA}_{1 \mathrm{c}}$ and glucose tests. Blood for the laboratory tests was not always collected on the same day as the POC test, as some remote clinics are only able to send laboratory samples for analysis once a week and often collect samples only on the day of transport. For the OGTT, we used a standard 2-hour $75 \mathrm{~g} / 300 \mathrm{~mL}$ glucose load (Carbotest, Lomb Scientific). ${ }^{5}$

Capillary blood $\mathrm{HbA}_{1 \mathrm{c}}$ concentration was measured in a finger-prick blood sample collected by primary health care providers and analysed on a DCA 2000+ Analyzer (Siemens/Bayer). This was the only POC machine available in Kimberley clinics during the period of the study, and is routinely used for assessing diabetic control. The aim of our study was to look at real-world practice, so we did not attempt to change the way staff undertook testing or to maintain or calibrate the machines. ${ }^{17}$

Venous whole blood samples were collected in fluoride/oxalate tubes (glucose test) or EDTA tubes $\left(\mathrm{HbA}_{1 \mathrm{c}}\right.$ test). Normal procedures at each clinic were used to store (whole blood was stored at $4^{\circ} \mathrm{C}$ ) and transport samples to one of the three Kimberley PathWest laboratories. Whole blood samples for $\mathrm{HbA}_{1 \mathrm{c}}$ testing were transported to the PathWest laboratory in Perth. The distances from the study sites to the Kimberley laboratories ranged from $2 \mathrm{~km}$ by road to $650 \mathrm{~km}$ by air, and from the Kimberley laboratories to Perth between $1677 \mathrm{~km}$ and $2224 \mathrm{~km}$ by air. Samples were received in Perth in 1-8 days.

Venous plasma $\mathrm{HbA}_{1 \mathrm{c}}$ levels were measured as part of routine PathWest work. PathWest uses an automated immunoassay, with anticoagulated whole blood specimens automatically haemolysed by $\mathrm{HbA}_{1 \mathrm{c}}$ haemolysis reagent in the predilution cuvette on a Cobas Integra 800 analyser (Roche Diagnostics). Total haemoglobin levels were measured colorimetrically, while $\mathrm{HbA}_{1 \mathrm{c}}$ levels were determined by immunoturbidimetric assay. The ratio of the $\mathrm{HbA}_{1 \mathrm{c}}$ concentration to that of total haemoglobin in the specimen yielded the final proportionate $\mathrm{HbA}_{1 \mathrm{c}}$ measurement.

Venous plasma glucose (PG) levels were measured by enzymatic assay (glucose oxidase spectrophotometric dry chemistry) on a Vitros 250 Analyser (Ortho Clinical Diagnostics) at the Kimberley PathWest laboratories.

\section{Comparison of the $\mathrm{HbA}_{1 \mathrm{c}}$ and glucose algorithms}

Participants were classified independently by each model for detecting diabetes. We then determined, using the same participants for each model, whether the $\mathrm{HbA}_{1 \mathrm{c}}$ algorithm was more likely than the glucose algorithm to:

- provide a rapid definitive result;

- detect cases of diabetes.

Initial classification by the $\mathrm{HbA}_{1 c}$ algorithm used the $\mathrm{POC} \mathrm{HbA}_{1 c}$ measurement, or the first laboratory $\mathrm{HbA}_{1 c}$ measurement if the POC test was not completed (five cases). Subsequent diagnosis of prediabetes and diabetes was based on POC and/or laboratory $\mathrm{HbA}_{\mathrm{lc}}$ measurements as follows.

- Normal: $\mathrm{POC}$ or laboratory $\mathrm{HbA}_{1 c}$ $<39 \mathrm{mmol} / \mathrm{mol}(<5.7 \%)$.

- Prediabetes: laboratory $\mathrm{HbA}_{1 \mathrm{c}}=39$ $46 \mathrm{mmol} / \mathrm{mol}(5.7 \%-6.4 \%)$.

- Diabetes: two diagnostic $\mathrm{HbA}_{1 \mathrm{c}}$ measurements $\geqslant 48 \mathrm{mmol} / \mathrm{mol}$ $(\geqslant 6.5 \%)$.

While ADA and WHO guidelines require two diagnostic laboratory results for diagnosing diabetes in asymptomatic patients, ${ }^{9,20}$ we used diagnostic POC results, with laboratory results confirming the diagnosis.

We based the initial classification using the glucose algorithm on the first laboratory PG measurement. Subsequent diagnosis of impaired glucose tolerance and diabetes was based on follow-up glucose tests as follows.

- Normal: PG level <5.5 mmol/L.

- Indeterminate (equivocal result): fasting PG (FPG) level 5.5$6.9 \mathrm{mmol} / \mathrm{L}$, or random PG (RPG) level $5.5-11.0 \mathrm{mmol} / \mathrm{L}$ with no completed follow-up tests.

- Impaired glucose tolerance: OGTT 2-hour PG level 7.8-11.0 mmol/L.

- Diabetes: one diagnostic OGTT result (FPG level $\geqslant 7.0 \mathrm{mmol} / \mathrm{L}$ or 2-hour PG level $\geqslant 11.1 \mathrm{mmol} / \mathrm{L}$ ), or two diagnostic glucose measurements (FPG level $\geqslant 7.0 \mathrm{mmol} / \mathrm{L}$ and/or RPG level $\geqslant 11.1 \mathrm{mmol} / \mathrm{L}$ ).

It was expected that participants with an initial laboratory $\mathrm{HbA}_{1 \mathrm{c}}$ value greater than $39 \mathrm{mmol} / \mathrm{mol}(5.7 \%)$ or a glucose level greater than $5.5 \mathrm{mmol} / \mathrm{L}$ were to be followed up with further tests (FPG, OGTT, $\mathrm{HbA}_{1 c}$ ) to confirm the abnormal result (Appendix). The researchers provided regular reminders to clinics to support follow-up. Participants were diagnosed with diabetes if they met any of the $\mathrm{HbA}_{1 c}$, OGTT- or glucose-based diagnostic criteria for diabetes, based on all measurements collected during the course of the study.

Barriers to and enablers of screening by each algorithm for detecting diabetes were documented during the study.

\section{Statistical analysis}

All analyses were performed with Stata, version 13 (StataCorp). We used the McNemar test for paired nominal data to compare differences between the two algorithms regarding the rates of screening for prediabetes and diabetes; between the rates of their diagnosis; and between the rates of obtaining a definitive result. Point estimates were presented with $95 \%$ CIs; the exact $P$ value was used. $P<0.05$ was defined as statistically significant.

\section{Ethics approval}

Ethics approval was obtained from the Human Research Ethics Committee of the University of Western Australia, the Western Australian Aboriginal Health Ethics Committee and the Western Australian Country Health Service (WACHS) Human Research Ethics Committee. This project was supported by the Kimberley Aboriginal Health Planning Forum Research Subcommittee..$^{21}$ 


\section{Results}

Two hundred and fifty-five participants were enrolled and assessed by both models for detecting diabetes (Box 1). Their median age was 36 years (range, 17-79 years) and 152 participants (59.6\%) were female.

Participants were significantly more likely to receive a definitive test result with the $\mathrm{HbA}_{1 \mathrm{c}}$ algorithm (250 of 255 participants; POC test completed in all but five cases) than with the glucose algorithm (214 of 255 participants: 41 cases were not screened or returned indeterminate results; McNemar odds ratio [OR], 10.0; 95\% CI, 3.6-38.5; $P<0.001$; Box 1). $\mathrm{HbA}_{1 c}$ results were also received much more rapidly; only six of 255 participants $(2.4 \%)$ had not received a result within 7 days. In contrast, 56 (22.0\%) of 255 participants had not received a definitive result within 7 days with the glucose algorithm, and 52 (20.4\%) had not received a definitive result within 28 days $(P<0.001)$.
Of the 255 participants, follow-up laboratory tests were planned for the $168(65.9 \%)$ with abnormal initial laboratory measurements (Appendix). These participants were significantly more likely to be followed up with laboratory $\mathrm{HbA}_{1 \mathrm{c}}$ tests than with fasting FPG tests or OGTTs (92 v 72 participants; $P=0.0051)$. Fifty-seven OGTTs were completed, including 49 of $117(41.9 \%)$ requested tests.

Participants were significantly more likely to be diagnosed with diabetes by the $\mathrm{HbA}_{1 \mathrm{c}}$ algorithm (15 diagnoses) than with the glucose algorithm (4 diagnoses; McNemar OR, 12.0; 95\% CI, 1.8-513; $P=0.003)$. While 16 of 255 participants were identified as having diabetes by one or both algorithms, an additional four participants were identified by supplementary OGTTs performed because of the study design, giving a total of 20 participants diagnosed with diabetes (Box 2). The five cases not identified with the $\mathrm{HbA}_{1 \mathrm{c}}$ algorithm (cases 16-20) had initially been classified as prediabetes; at the time of the diagnostic OGTT, one person had a $\mathrm{HbA}_{1 \mathrm{c}}$ measurement that was also diagnostic for diabetes (Box 2).

Of the 187 participants whose initial glucose measurements were normal, eight $(4.3 \%)$ were diagnosed with diabetes - either as the result of two diagnostic $\mathrm{HbA}_{1 \mathrm{c}}$ results (cases 4-7) or of a diagnostic OGTT result (cases 17-20) (Box 2). For seven participants, diabetes was confirmed within 2 months, and for the eighth participant, after 6 months. None of the 137 participants with a POC $\mathrm{HbA}_{1 \mathrm{c}}$ measurement of less than $39 \mathrm{mmol} / \mathrm{mol}$ were subsequently diagnosed with diabetes.

\section{Discussion}

Our study showed that testing for diabetes by $\mathrm{HbA}_{1 \mathrm{c}}$ assessment in Aboriginal populations in remote towns and communities was

\section{Comparison of the glycated haemoglobin $\left(\mathrm{HbA}_{\mathrm{lc}}\right)$ and standard glucose algorithms for classifying} participants

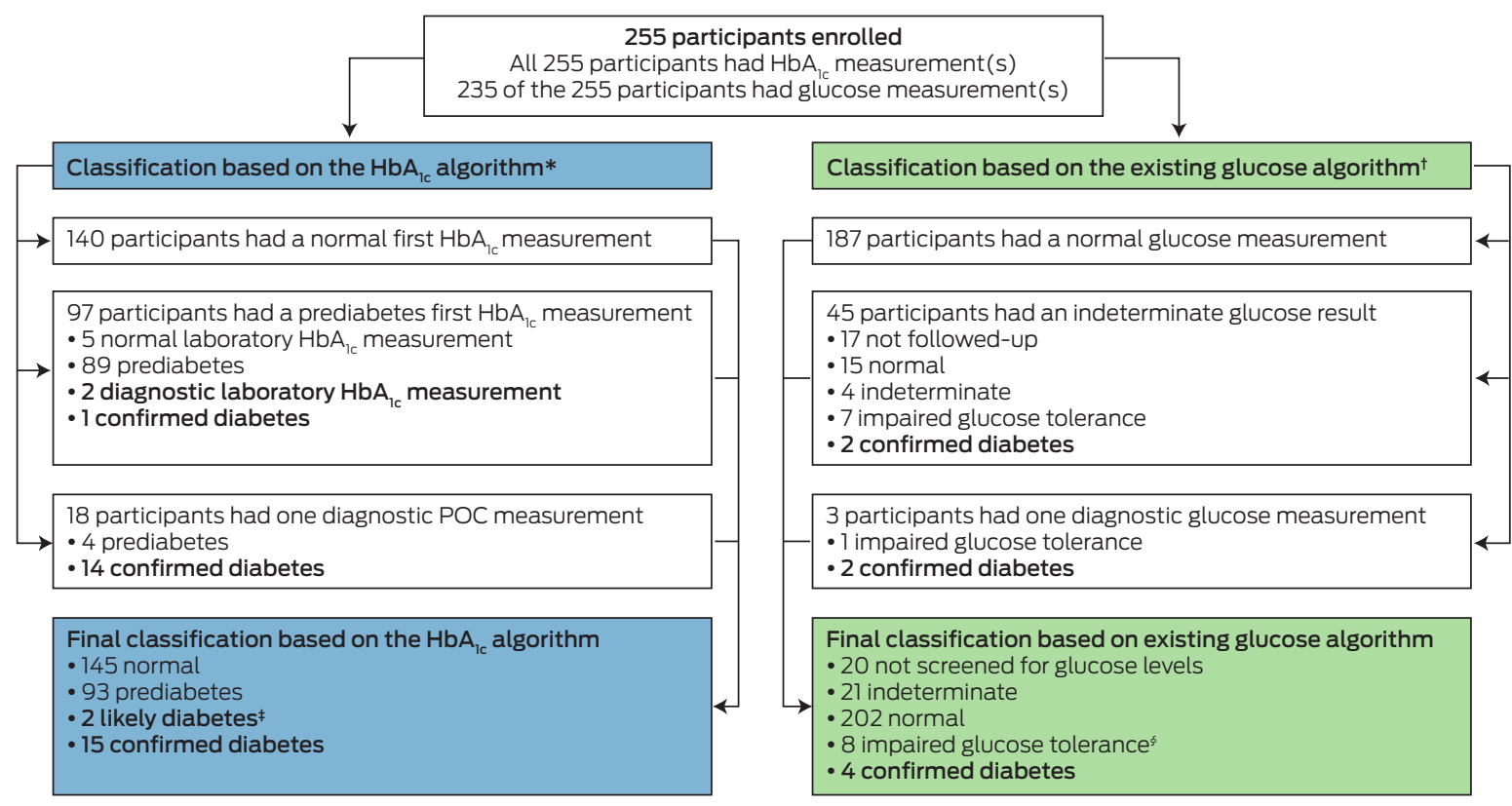

$\mathrm{POC}=$ point-of-care

* Initial classification was based on the POC $\mathrm{HbA}_{1 \mathrm{c}}$ measurement, or on the first laboratory HbA $\mathrm{A}_{1 \mathrm{c}}$ measurement if the POC test was not completed (five cases). Subsequent diagnosis of prediabetes was based on the first laboratory $\mathrm{Hb} \mathrm{A}_{1 \mathrm{c}}$ measurement, or on the POC measurement if the laboratory test

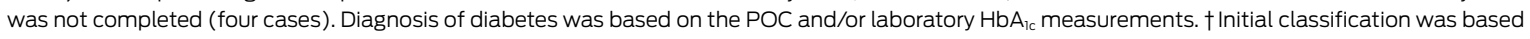
on the first laboratory glucose measurement. Subsequent diagnosis of impaired glucose tolerance and diabetes was based on follow-up laboratory glucose measurements or an oral glucose tolerance test. $¥$ Two participants each had one diagnostic laboratory $\mathrm{Hb} \mathrm{A}_{1 \mathrm{c}}$ result that was not followed up; in contrast to American Diabetes Association guidelines, which require a confirmatory test in asymptomatic patients, ${ }^{20}$ the Australian Medical Services Advisory Committee ${ }^{13}$ does not consider a confirmatory test to be necessary for diagnosing diabetes. $\$$ Seven participants had impaired glucose tolerance; one participant was diagnosed with gestational diabetes 378 days after enrolling. 
2 Glycated haemoglobin $\left(\mathrm{HbA}_{1 c}\right)$ and glucose measurements of 20 participants who received a confirmed diabetes diagnosis*

\begin{tabular}{|c|c|c|c|c|c|c|}
\hline \multirow[b]{2}{*}{ Case } & \multicolumn{3}{|c|}{$\begin{array}{l}\mathrm{HbA}_{\mathrm{lc}} \text { measurements } \\
\mathrm{mmol} / \mathrm{mol}(\%)\end{array}$} & \multicolumn{3}{|c|}{$\begin{array}{l}\text { Glucose measurements } \\
\mathrm{mmol} / \mathrm{L}\end{array}$} \\
\hline & $\begin{array}{c}\text { Point-of-care } \\
\text { value }\end{array}$ & $\begin{array}{c}\text { Initial laboratory } \\
\text { value }\end{array}$ & $\begin{array}{l}\text { Repeat laboratory } \\
\text { value }\end{array}$ & $\begin{array}{l}\text { Initial laboratory } \\
\text { value }\end{array}$ & $\begin{array}{c}\text { Repeat laboratory } \\
\text { value/ } \\
\text { OGTT value (0-hr) }\end{array}$ & $\begin{array}{l}\text { OGTT value } \\
\text { (2-hr) }\end{array}$ \\
\hline \multicolumn{7}{|c|}{ Diagnosed by both algorithms } \\
\hline 1 & $60(7.6)$ & $58(7.5)$ & $58(7.5)[d 7]$ & FPG: 6.2 & FPG: $6.2[d 7)$ & 16.8 \\
\hline 2 & $67(8.3)$ & $66(8.2)$ & $68(8.4)[d 11]$ & RPG: 12.3 & FPG: 7.9 [d11] & - \\
\hline 3 & $102(11.5)$ & $101(11.4)$ & $77(9.2)[d 135]$ & RPG: 14.9 & RPG: 12.9 [d37] & - \\
\hline \multicolumn{7}{|c|}{ Diagnosed using the $\mathrm{HbA}_{1 c}$ but not the glucose algorithm } \\
\hline 4 & $46(6.4)$ & $48(6.5)$ & $53(7.0)[d 41]$ & FPG: 5.4 & FPG: $5.6^{\dagger}[\mathrm{d} 41]$ & - \\
\hline 5 & $48(6.5)$ & $48(6.5)$ & $49(6.6)[d 32]$ & FPG: 4.9 & FPG: 4.8 [d32] & 6.6 \\
\hline 6 & $48(6.5)$ & $48(6.5)$ & - & RPG: 4.9 & RPG: 4.9 [d503] & - \\
\hline 7 & $49(6.6)$ & $49(6.6)$ & $52(6.9)[d 51]$ & RPG: 4.1 & FPG: 4.8 [d89] & - \\
\hline 8 & $48(6.5)$ & $48(6.5)$ & - & RPG: 6.2 & - & - \\
\hline 9 & $49(6.6)$ & $49(6.6)$ & 45 (6.3) [d413] & RPG: 5.7 & FPG: 5.0 [d386] & - \\
\hline 10 & $49(6.6)$ & $51(6.8)$ & - & RPG: 6.2 & - & - \\
\hline 11 & $51(6.8)$ & $52(6.9)$ & $50(6.7)[d 27]$ & RPG: 6.5 & FPG: 5.7 [d30] & $9.6^{\dagger}$ \\
\hline 12 & $52(6.9)$ & $54(7.1)$ & $52(6.9)[\mathrm{d} 18]$ & RPG: 5.5 & FPG: 5.5 [d18] & $9.5^{\dagger}$ \\
\hline 13 & $54(7.1)$ & $56(7.3)$ & - & RPG: 9.3 & - & - \\
\hline 14 & $54(7.1)$ & $60(7.6)$ & - & RPG: 6.7 & - & - \\
\hline 15 & $56(7.3)$ & $60(7.6)$ & -- & FPG: 5.6 & FPG: 5.6 [dO] & $11.0^{\dagger}$ \\
\hline \multicolumn{7}{|c|}{ Diagnosed using the glucose but not the $\mathrm{HbA}_{1 c}$ algorithm } \\
\hline 16 & $46(6.4)$ & $46(6.4)$ & $39(5.7)[d 295]$ & RPG: 8.2 & FPG: 5.3 [d273] & 11.7 \\
\hline \multicolumn{7}{|c|}{ Diagnosed using OGTT requested due to abnormal $\mathrm{HbA}_{1 c}$ paired with normal initial glucose result } \\
\hline 17 & $39(5.7)$ & $41(5.9)$ & $39(5.7)[d 172]$ & FPG: 5.1 & FPG: 4.4 [d172] & 12.3 \\
\hline 18 & $40(5.8)$ & $41(5.9)$ & $50\left(6.7^{f}\right)[d 56]$ & FPG: 4.4 & FPG: 7.2 [d56] & 10.6 \\
\hline 19 & $41(5.9)$ & $41(5.9)$ & $44(6.2)$ [d193] & RPG: 4.7 & FPG: 4.1 [d42] & 12.5 \\
\hline 20 & $43(6.1)$ & $45(6.3)$ & 45 (6.3) [d45] & RPG: 4.6 & FPG: 5.2 [d45] & 12.7 \\
\hline
\end{tabular}

POC = point-of-care. OGTT = oral glucose tolerance test. FPG = fasting plasma glucose level. RPG = random plasma glucose level. $d=$ days since enrolment.

* Diagnostic diabetes measurements are printed in boldface. † Impaired glucose tolerance. ‡OGTT commenced, but 2-hour blood sample not collected. § Diagnostic HbA $\mathrm{I}_{\mathrm{lc}}$ measurement at the time the OGTT was done.

significantly more likely to detect diabetes than glucose testing, and that a definitive result could be obtained more rapidly.

It is of concern that only four of the 20 participants diagnosed with diabetes were identified with the glucose algorithm. In our study, six participants were diagnosed by OGTT, but four of these had normal FPG values. While our results are based on small numbers, this suggests the FPG is not sufficiently sensitive as a screening test in this population.

In contrast, all participants with a confirmed diagnosis of diabetes were identified by the $\mathrm{HbA}_{1 \mathrm{c}}$ algorithm as having either diabetes (15 cases) or prediabetes (five cases). Those classified as having prediabetes are expected to be followed up more frequently, reducing the chance of diabetes in these patients being missed for any length of time. $\mathrm{HbA}_{1 \mathrm{c}}$ testing is clearly more likely to detect diabetes than glucose testing.

Our study had a relatively complicated protocol because it compared two diagnostic algorithms. Unsurprisingly, adherence to these protocols was not always complete, but adherence to OGTT (42\%) was better than in another recent Australian study $(27 \%){ }^{22}$ and better than would be expected from the usual experience of remote Aboriginal health practice. This improvement was probably due to regular reminders provided by the researchers. Initial adherence to $\mathrm{HbA}_{1 \mathrm{c}}$ testing was excellent, but only $55 \%$ of those who required follow-up $\mathrm{HbA}_{1 \mathrm{c}}$ assessment were actually tested, with staff reporting the following barriers to follow-up testing:
- Waiting for participants to return while fasting, so that blood for $\mathrm{HbA}_{1 \mathrm{c}}$ and glucose tests could be collected at the same time.

- High workforce turnover. Some clinicians who were reviewing results did not realise that some "patients" were study participants, assuming they had already been diagnosed with diabetes; they considered $\mathrm{HbA}_{1 \mathrm{c}}$ values of $48-$ $52 \mathrm{mmol} / \mathrm{mol}(6.5 \%-6.9 \%)$ as indicating good glycaemic control and decided that a further $\mathrm{HbA}_{1 \mathrm{c}}$ test was unwarranted.

- Field officers tasked with bringing participants to the clinics often had extensive lists of patients; reviewing blood tests was often a lower priority. 
3 Kimberley algorithm for screening for and diagnosing diabetes using point-of-care $(\mathrm{POC})$ and laboratory $(\mathrm{lab})$ glycated haemoglobin $\left(\mathrm{HbA}_{1 c}\right)$ testing ${ }^{19,24}$

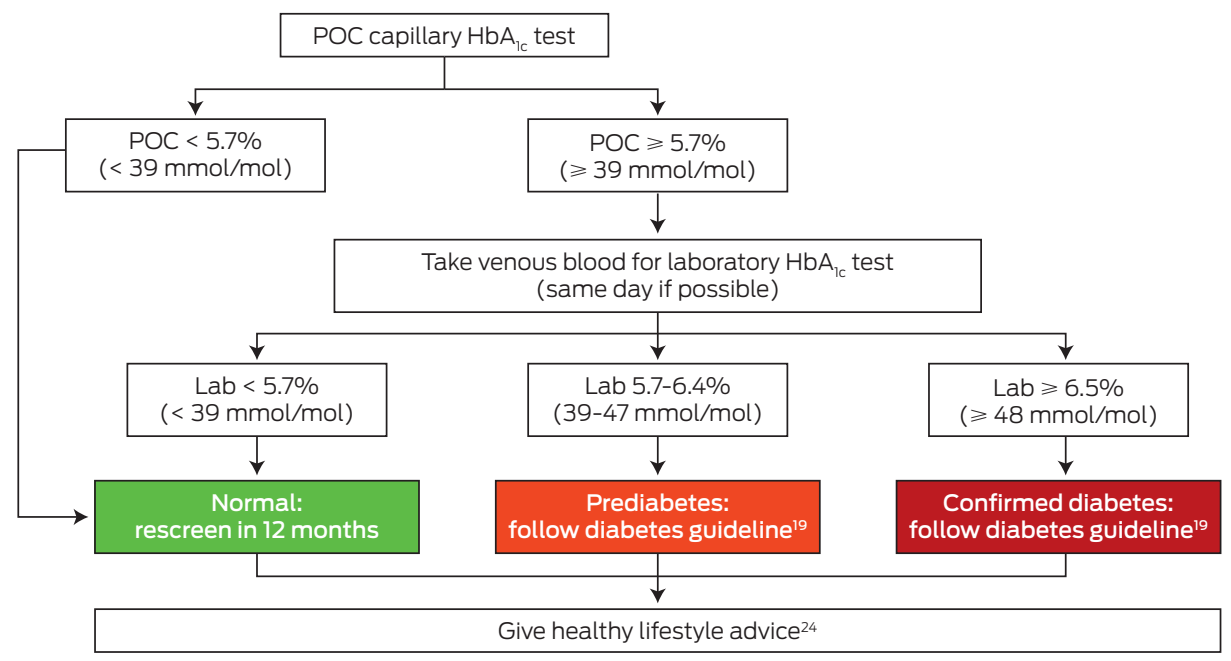

- Participants refusing the OGTT or leaving before the 2-hour sample had been collected.

Our results highlight the need for simplified testing regimens. For asymptomatic individuals, ADA and $\mathrm{WHO}$ recommend a confirmatory test as soon as practical..$^{9,20}$ However, as $\mathrm{HbA}_{1 \mathrm{c}}$ testing is more robust and reproducible than glucose testing, MSAC does not consider a confirmatory test necessary; ${ }^{13}$ further, there is only one MBS rebate for $\mathrm{HbA}_{1 \mathrm{c}}$ screening in any 12-month period. ${ }^{14}$

Reducing the number of laboratory tests will further improve screening and diagnosis, and the Kimberley $\mathrm{HbA}_{1 \mathrm{c}}$ algorithm has been updated to reflect this (Box 3). If the POC $\mathrm{HbA}_{1 c}$ result is abnormal ( $\geqslant 39 \mathrm{mmol} / \mathrm{mol}$ $[5.7 \%])$, we recommend that venous blood be collected on the same day for a confirmatory laboratory $\mathrm{HbA}_{1 \mathrm{c}}$ test. If the POC result is high (the cut-point could be determined locally) then baseline assessments (eg, cardiovascular risk factors, kidney function) for newly diagnosed patients can be requested at the same time as the confirmatory laboratory $\mathrm{HbA}_{1 \mathrm{c}}$ test, again potentially reducing the number of clinical visits and venepunctures needed.

An additional advantage to the patient of an immediate result is that they know straight away whether the result is normal (55\% in our study) ${ }_{1}^{17}$ which would avoid the need to return for a clinical review (charged to MBS). Other potential cost savings include reduced specimen collection (patient and staff time, consumable costs) and transportation of blood samples from remote communities to Perth. Consumer costs, such as patient time, can affect compliance ${ }^{23}$ and are thus an important element of diabetes testing in this population. If patients are not having other laboratory blood tests, POC testing will avoid the need for venepuncture, which may make screening more acceptable to some patients, potentially increasing uptake. This can be expected to further improve screening and diagnosis in remote areas and the timeliness of initiating management, including lifestyle advice and pharmacotherapy.

Further research is required to determine the cost-effectiveness of the Kimberley $\mathrm{HbA}_{1 \mathrm{c}}$ algorithm compared with screening in remote locations by laboratory $\mathrm{HbA}_{1 \mathrm{c}}$ testing alone, and for using simplified POC accreditation processes. $^{17}$

Potential barriers to implementing $\mathrm{HbA}_{1 \mathrm{c}}$ testing include a lack of familiarity with the test as a diagnostic tool. Further, as the MBS rebate has only recently been announced, it is not currently a routine test for people without diabetes. Together with updated protocols, changes to the way laboratories report $\mathrm{HbA}_{1 \mathrm{c}}$ results of diagnostic tests will be needed to highlight new diagnoses of prediabetes and diabetes.
Modifications of how medical software processes these tests may also be needed, as well as extensive education for health service providers.

A change from glucose to $\mathrm{HbA}_{1 \mathrm{c}}$ testing would substantially increase the number of people needing active follow-up (93 instances of prediabetes, compared with 7 of impaired glucose tolerance; Box 1), potentially leading to overdiagnosis of prediabetes. While this would add to the workload of health service providers, identifying more people at increased risk could also improve targeting of attempts to reduce risk early in the disease process. Further research is required to consider the appropriateness of the prediabetes cut-point used in our study and whether differing levels of intervention are appropriate within the $\mathrm{HbA}_{1 \mathrm{c}} 39-64 \mathrm{mmol} / \mathrm{mol}$ (5.7\%-6.4\%) range.

The strength of our study is that it reflects the practicalities of diabetes detection in remote locations; staff were trained in-house to use the POC $\mathrm{HbA}_{1 \mathrm{c}}$ analyser and existing processes for laboratory $\mathrm{HbA}_{1 \mathrm{c}}$ measurement were used. The limitations of our study included the use of a convenience sample that may not be representative of the entire Kimberley adult Aboriginal population. Further, not all participants with abnormal laboratory measurements could be located for follow-up laboratory tests, resulting in incomplete data, and there were variations in adherence to the study protocol for follow-up tests.

Our study shows that adopting the Kimberley $\mathrm{HbA}_{1 \mathrm{c}}$ algorithm may simplify the testing process in previously undiagnosed individuals and provide a timelier and more accurate diagnosis of diabetes for Aboriginal people and other high-risk remote populations in Australia and elsewhere in the world.

Acknowledgements: We thank the staff and patients of Broome Regional Aboriginal Medical Service, Derby Aboriginal Health Service, Yuri Yungi Medical Service, and the Balgo, Bidyadanga and Warmun health care clinics for participating in this study. We thank Sharon Evans for expert statistical advice; Graeme Maguire, Jaye Martin and Carmel Nelson for their contributions to the study design, and Alexander King and Malcolm King for critically reviewing the manuscript. This project was funded in part through a Small Project Grant by the Rural Clinical School of Western Australia.

Competing interests: No relevant disclosures.

Received 11 Nov 2014, accepted 21 Apr 2015.

References are available online at www.mja.com.au. 
1 Hoy WE, Wang Z, Baker PR, Kelly AM. Secondary prevention of renal and cardiovascular disease: results of a renal and cardiovascular treatment program in an Australian Aboriginal community. J Am Soc Nephrol 2003; 14 Suppl 2: S178-S185.

2 Holman RR, Paul SK, Bethel MA, et al. 10-year follow-up of intensive glucose control in type 2 diabetes. N Engl J Med 2008; 359: 1577-1589.

3 Holman RR, Paul SK, Bethel MA, et al. Long-term follow-up after tight control of blood pressure in type 2 diabetes. $N$ Engl J Med 2008; 359: 1565-1576.

4 Dunstan DW, Zimmet PZ, Welborn TA, et al. The rising prevalence of diabetes and impaired glucose tolerance: the Australian Diabetes, Obesity and Lifestyle Study. Diabetes Care 2002; 25: 829-834.

5 Colagiuri S, Davies D, Girgis S, Colagiuri R. National evidence based guideline for case detection and diagnosis of type 2 diabetes. Canberra: Diabetes Australia, NHMRC, 2009. http://www. nhmrc.gov.au/guidelines/publications/ di17 (accessed Jan 2015).

6 Marley JV, Nelson C, O'Donnell V, Atkinson D. Quality indicators of diabetes care: an example of remotearea Aboriginal primary health care over 10 years. Med J Aust 2012; 197: 404-408.

7 American Diabetes Association. Standards of medical care in diabetes - 2010. Diabetes Care 2010; 33 Suppl 1 : SII-S6l.

8 Degeling C, Rock M, Rogers WA. Testing relationships: ethical arguments for screening for type 2 diabetes mellitus with HbAlC. J Med Ethics 2012; 38 : 180-183.

9 World Health Organization. Use of glycated haemoglobin (HbAlc) in the diagnosis of diabetes mellitus. Diabetes Res Clin Pract 2011; 93: 299-309.
10 John WG, UK Department of Health Advisory Committee on Diabetes. Use of $\mathrm{HbA}_{\mathrm{lc}}$ in the diagnosis of diabetes mellitus in the UK. The implementation of World Health Organization guidance 2011. Diabet Med 2012; 29: 1350-1357.

1 New Zealand Society for the Study of Diabetes. NZSSD position statement on the diagnosis of, and screening for, Type 2 diabetes. Sep 2011. http://www. nzssd.org.nz/HbAlc/1.\%20NZSSD\%20 position\%20statement\%20on\%20 screening\%20for\%20type $\% 202 \% 20$ diabetes\%20final\%20Sept\%202011. pdf (accessed May 2015).

12 d'Emden MC, Shaw JE, Colman PG, et al. The role of $\mathrm{HbA}_{\mathrm{c}}$ in the diagnosis of diabetes mellitus in Australia. Med $J$ Aust 2012; 197: 220-221.

13 Department of Health (Australia). MSAC completed assessments and reviews. 1267 - HBAlc test for the diagnosis of diabetes mellitus. http:// www.msac.gov.au/internet/msac/ publishing.nsf/Content/1267-public (accessed Apr 2015).

14 Department of Health (Australia). MBS online. The November 2014 Medicare Benefits Schedule. http://www.health. gov.au/internet/mbsonline/publishing. nsf/Content/Downloads-2014-11 (accessed Jan 2015).

15 Martin DD, Shephard MDS, Freeman H, et al. Point-of-care testing of $\mathrm{HbA}_{\mathrm{c}}$ and blood glucose in a remote Aboriginal Australian community. Med J Aust 2005; 182: 524-527.

16 Shemesh T, Rowley KG, Shephard M, et al. Agreement between laboratory results and on-site pathology testing using Bayer DCA2000+ and Cholestech LDX point-of-care methods in remote Australian Aboriginal communities. Clin Chim Acta 2006; 367: 69-76.

17 Marley JV, Oh MS, Hadgraft N, et al. Cross-sectional comparison of point-of-care with laboratory $\mathrm{HbA}_{k c}$ in detecting diabetes in real-world remote Aboriginal settings. BMJ Open 2015; 5: e006277.

18 Shephard MD. Cultural and clinical effectiveness of the 'QAAMS' pointof-care testing model for diabetes management in Australian Aboriginal Medical Services. Clin Biochem Rev 2006; 27: 161-170.

19 Kimberley Aboriginal Medical Services Council, WA Country Health Service Kimberley. Chronic disease protocols: diabetes type I. Jan 2013. http:// resources.kamsc.org.au/downloads/ cd_dtii.pdf (accessed Jan 2015).

20 American Diabetes Association. Standards of medical care in diabetes - 2014. Diabetes Care 2014; 37 Suppl 1: S14-S80.

21 Mc Loughlin F, Hadgraft NT, Atkinson $D$, et al. Aboriginal health research in the remote Kimberley: an exploration of perceptions, attitudes and concerns of stakeholders. BMC Health Serv Res 2014; 14: 517.

22 Valentine NA, Alhawassi TM, Roberts $\mathrm{GR}$, et al. Detecting undiagnosed diabetes using glycated haemoglobin: An automated screening test in hospitalised patients. Med J Aust 2011; 194: 160-164.

23 Levin B, Smith RA, Feldman GE, et al. Promoting early detection tests for colorectal carcinoma and adenomatous polyps. A framework for action: the strategic plan of the National Colorectal Cancer Roundtable. Cancer 2002; 95: 1618-1628.

24 Kimberley Aboriginal Medical Services Council, WA Country Health Service Kimberley. Healthy Living. Chronic disease protocols. Undated. http:// resources.kamsc.org.au/downloads/ cd_hl.pdf (accessed Feb 2015). 